\title{
BARRIERS TO PRISONERS' RE-ENTRY INTO FORMAL AND INFORMAL LABOUR MARKET
}

\author{
Taksaorn Phuchongpravech* \\ Chulalongkorn University \\ Thanee Chaiwat \\ Chulalongkorn University
}

\begin{abstract}
Aside from academics suggesting that low-physical-attractive prisoners may face difficulty reentering the labour market: permitting employers to access criminal history records aggravates the situation. The current study aims to alleviate this discrimination by generating more beauty premiums to prisoners through cosmetic surgery. The choice experiments (CEs) on hypothetical cosmetic surgery faces of 18 Thai male prisoners were conducted. In which every choice set, the respondents were required to make a tradeoff between beauty and criminal history records. The results show that cosmetic surgery generates beauty premiums to prisoners in both the formal and informal sectors with the odds ratio or increase of the utility of 1.75 and 1.754 , respectively. Contrarily, the criminal history records result in discrimination to prisoners' employments: decreasing job opportunities by $82.8 \%$ and $51 \%$ in the formal and informal sectors, respectively. The MWTP values show an additional salary to the cosmetic surgery groups for 2,600 baht approximately in both sectors. Besides contributing to the literature, the current study sheds light on the importance of physical appearance and criminal history records as one of the main barriers to prisoners' re-entry. The findings could serve as new knowledge for policymakers to improve the success rate of prisoners' reintegration.
\end{abstract}

Keywords: Beauty Premium, Choice Experiment, Cosmetic Surgery, Criminal History Record, Physical Attractiveness, Prisoner Employment.

Received: 31 March 2020

Accepted: 30 December 2020

https://doi.org/10.33736/ijbs.3190.2021

\section{INTRODUCTION}

It's been decades that academics have been investigating the impact of criminal history records: documenting it as the main barrier to prisoners' labour market re-entry while secured employment is a significant element of prisoners' reintegration. The ex-prisoners themselves also revealed the experience of the negative impact of criminal history records on their employment opportunities. (Chui \& Cheng, 2013; Decker, Ortiz, Spohn, \& Hedberg, 2015; Kim \& Loury, 2018; Pager, 2003; Pager, Western, \& Sugie, 2009; Visher, Debus-Sherrill, \& Yahner, 2011) However, other academics argued that the close-records policy might cause statistical discrimination against the vulnerable demographic group (e.g., African-Americans), whereas the open-records policy might increase the re-entry success rate and wage of the no criminal history individuals, which may

\footnotetext{
* Corresponding author: Faculty of Economics, Chulalongkorn University, 254, Phayathai Road, Pathumwan, Bangkok 10330, Thailand. Email: Taksaorn.P@Chula.ac.th
} 
ultimately increase the average market wage where ex-convicts can free ride these premiums (Bushway, 2004; Holzer, Raphael, \& Stoll, 2006; Solinas-Saunders, Stacer, \& Guy, 2015). Whereas the argument between open and close records system remains, the prisoners continue to face difficulties reentering the labour market worldwide, including Thailand's prisoners. Let alone 'criminal history records' as the main re-entry barrier, a prisoner's physical appearance was also claimed to be another cause of social rejection, including employment discrimination (Kurtzberg, Safar, \& Mandell, 1969; Spira, Chizen, Gerow, \& Hardy, 1966). The issue motivated plastic surgeons and scholars to examine the rehabilitation quality of plastic/cosmetic surgery in inmates in many State prison systems. Their results showed decreases in recidivism rates of the cosmetic surgery group compared to baseline statistics (Freedman, Warren, Cunningham, \& Blackwell, 1988; Spira et al., 1966). Even though some might argue that their findings are rather weak, large 'economics of beauty' literature has proved that 'beauty' is a valuable characteristic in the labour market. That, by statistics, attractive individuals have more: job opportunity, occupational success, and a spouse whose potential earning are higher. (Biddle \& Hamermesh, 1998; Bóo, Rossi, \& Urzúa, 2013; Cawley, 2004; Fletcher, 2009).

Thai prisoner population has now reached 354,905 by July 2019, increasing from 182,032 in 2008 (Department of Corrections, 2020c): addressing a substantial number of people ending up with stain histories. Some Thai academics even defined them as the new-poor-people due to the smallscale of welcome by society. This discrimination in Thailand could cause by many factors, but the media's daily reports of crimes and crime-related TV programmes can be considered as one of the main influences of the impediment. While Eschholz (2002) and Young and Powell (2015) also suggested that crime-related-programme increased individual's fear of crime which may lead to discrimination on minorities (e.g., African-Americans and ex-prisoners). The media of which, to some extent, the broadcasted messages were unintentionally manifest negative image to all prisoners as dangerous and untrustworthy. Although the statistics showed the only minority of $14.38 \%$ of violent criminals in the Thai prisoners' population (Department of Corrections, 2020a). Moreover, the criminal history records discrimination has been aggravated due to the increasing number of employers' access to this information each year. Meanwhile, the current policy implementation in Thailand did not provide sufficient improvement of prisoners' success rate. For that, the increasing number of prisoners and employers participating in the reintegration programmed did not contribute to a decrease in the recidivism rate. On the other hand, the statistics reported the increase in recidivism rates: from $14.93 \%$ in 2017 to $15.65 \%$ in 2018 (Department of Corrections, 2020b), implying the failure to prisoners seeking employment legally as academics suggested employment plays a significant role in decreasing this rate (Siwach, 2018). While the academics' ongoing debates about open and close records policy cannot offer an optimal conclusion and the current policies of Thailand cannot yield a significant alleviation, we propose another alternative to alleviate discrimination by introducing the manifestation of the 'beauty premiums'

Given that literature exhibited the existence of beauty premiums and criminal records discrimination. We aim to examine the labour market impacts of these barriers where they were together investigated within a hiring decision. The beauty premium concept was applied when we used the simulation of cosmetic surgery to rebrand ex-prisoners and experimentally released them to the formal and informal labour sectors, accordingly. Owing to the experiments, we were able to simulate the hiring situation to observed employers' decision making and exhibited how the discrimination against prisoners in the Thai labour market could take place. Our findings could 
serve as a new piece of information to policymakers when it raises awareness of the significance of beauty and criminal history records concerning prisoners' employment in Thailand. This is for improving the success rate of labour market re-entry to this minority group and indirectly bringing back the human resource to the Thai workforce. The body of knowledge, to some extent, could also be applied for the phenomenal of prisoners' re-entry in some other Asian countries of which the society shares beliefs and values. The paper is organised as follows: Section 1, the introduction. Section 2, the related literature. Section 3, the methodology. Section 4, data. Section 5, the modeling strategy and results. And Section 6, the discussion and policy implications.

\section{RELATED LITERATURE}

\subsection{Discrimination Towards Race, Ethnicity, and Criminal History}

Bendick, Jackson, and Reinoso (1994) investigated racial discrimination in America where matched pairs of minority and nonminority were used to measure employers' responses to the personal characteristic of job seekers. Of whom the fictitious resumes were manipulated and sent to job posts. They found that African Americans were more than $20 \%$ treated less favourably than equally qualified nonminority. Solinas-Saunders et al. (2015) supported Bushway (2004)'s argument that close-records policy could cause statistical discrimination against the vulnerable demographic group (e.g., prisoners). Using the same approach as in Bendick et al. (1994) with the assumption that employers believed ex-prisoners were less productive, Solinas-Saunders et al. (2015) further exhibited that when criminal information was closed, the race became a proxy for a criminal conviction. The employers who were not informed of the applicant's true status would be willing to offer lower wages to black applicants and suggested that open-records policy might cause adverse selection: forcing high productivity workers to sort themselves in markets where they can distinguish themselves while employers end up hiring lower productivity workers.

Nevertheless, other academics argued it differently. An interchangeable approach of fictitious matched pairs resumes was used to investigate the impact of criminal history records and race. Pager (2003) showed that criminal history records represented the main barrier to employment with the significant effect of racial disparities: the criminal records reduced the likelihood of callback by $50 \%$ for white and $64.29 \%$ for black job applicants. Later, Pager et al. (2009) reconducted field experiments throughout New York City and added that despite white and black applicants being equally qualified, black applicants received $50 \%$ less call back compared to white applicants. Moreover, the criminal history records had a significantly stronger-negative impact, particularly for blacks, while black and Latino applicants with clean history were treated no better than white felon just released from prison. Decker et al. (2015), Agan and Starr (2017), and Ahmed and Lång (2017) further investigated the criminal records discrimination in the American and Swedish labour market for many occupations. Sequentially, they documented the empirical evidence supporting previous studies in which race, ethnicity, and stained history remained crucial barriers preventing the success of labour market re-entry.

However, in Asian perspectives, Chui and Cheng (2013) evidenced discrimination through the eyes of the ex-prisoners in Hong Kong. The qualitative semi-structured in-depth interviews were conducted with 16 formerly incarcerated Hong Kong Chinese young men. Whose mean age of 21.6 and had been convicted for offences related to dishonesty, such as theft, drugs offences, wounding, 
and sexual offences were conducted. The results showed ex-prisoners' difficulties finding legitimate employment and reports of being discriminated against, especially by prospective employers. Despite the government promotion of equal treatment for rehabilitated individuals, there still ongoing discrimination. Since there were reports of strong sense of perceived discrimination and the feeling that society inspected them as potential threats. Moreover, the author further addressed this discrimination in capitalist Hong Kong was a great challenge where the social safety net (SSN) was not as healthy as in other Western countries.

\subsection{Discrimination Towards Physical Appearance}

Where there are employment discriminations regarding race, ethnicity, and criminal history records, discrimination can also purely come from physical appearance. For that, the low-physical attractiveness, obesity, and short body result in earning disadvantages and lower job opportunities: the so-called 'labour penalties' After psychologists recurrently showed that attractive individuals are stereotyped as more brilliant, highly personable, expected to lead more successful lives, and evaluated as more productive (Berscheid \& Walster, 1974; Dipboye, Arvey, \& Terpstra, 1977; Dipboye, Fromkin, \& Wiback, 1975), the economists merged the beauty rating scores with workers' incomes to measure the outcome in the labour market. When holding equivalent for education, age, family background, and other characteristics: there is an impact of weight, height, and physical attractiveness on workers' earnings and household incomes in many professions worldwide, such as workers in British, America, and German (Cawley, 2004; Fletcher, 2009; Harper, 2000; Oreffice \& Quintana-Domeque, 2016), instructors and lawyers in America (Babin, Hussey, Nikolsko-Rzhevskyy, \& Taylor, 2020; Biddle \& Hamermesh, 1998), and workers in Taiwan and Indonesia (Sohn, 2015; Tao, 2014). Such impacts exhibited that while short and obese individuals were at a disadvantage from the labour market penalties, the attractive individuals enjoyed the so-called beauty premiums. By receiving more earning, being more successful, being able to start their own business faster, and having a spouse whose earning ability is higher.

From the experiment perspective, Berggren, Jordahl, and Poutvaara (2010) were ones who scrutinised the beauty premiums of the political candidates in Finland. The objective was to examine the correlation between beauty and electoral success based on the assumption that goodlooking politicians would receive more votes. The online surveys were conducted in German, France, Denmark, Finland, and outside Finland on a total of 10,011 university and college respondents who presented with the candidates' campaign photos. Despite controlling for education and occupation, the beautiful politician received more votes: an increase in a measure of beauty by one standard deviation associated with an increase of $20 \%$ and $17 \%$ in the number of votes for average non-incumbent parliament candidates and municipal election, respectively. Later, Bóo et al. (2013) analysed in a greater depth the hiring process in multiple occupations when a large number of fictitious resumes were manipulated and sent to employment ads posted in Argentina. Supporting former studies, the attractive workers received $36 \%$ more callback and being contacted sooner.

\subsection{Purchasing Beauty and its Return}

Concerning the investment side of beauty, the actual cosmetic procedures performed in the prisoner population in America contributed to the deceases in the recidivism rates below based-line in the cosmetic surgery group (Freedman et al., 1988; Spira et al., 1966). These phenomenal also 
materialized in the non-prisoner population in Asian countries, such as South Korea and China. Hamermesh, Meng, and Zhang (2002) investigated the reverse perspective of the beauty premiums where women in Shanghai, China, invested in beauty related products to enhance their looks, which in turn paid back in terms of the higher incomes. Their results showed that women's spending on clothing and cosmetics paid back no more than $15 \%$ of an additional unit of expense in the form of higher-earning. Even though such spending considered as consumption rather than an investment. However, it produced an increase in some productivity-enhancing characteristics. Adding on Hamermesh et al. (2002)'s study, Lee and Ryu (2012) were among the first who investigated the impact of economics returns to facial plastic surgery in Korea. By merging the income from the dating service data set with the beauty scores from the surgery inquirer data sets, they showed that the plastic surgery increased the surgery inquirers' facial attractiveness. And such an increase in beauty not only associated with the monetary benefits in the labour market but also marriage markets. Wherein the additional incomes for both genders were found from marrying a richer spouse. This is significant as they were able to show the labour market outcome of the 'purchasing beauty' perspective, especially the purchase of cosmetic surgery.

Thus, with all have been elaborated, the related literature on both discriminations towards criminal history records and physical attractiveness between Western and Asian countries showed that these types of discrimination seemed to be indifferent. And the regions did not give exemptions of discriminations to those who are ex-prisoners. However, the reservation found that existing studies often relied on a small number of beauty assessors who were not the employer themselves. Moreover, when the rating scores were retrieved by rating photographs, which came from multiple sources, such as in Berggren et al. (2010), the inconsistent quality of the photos might result in the inaccuracy of beauty assessment. Furthermore, when Lee and Ryu (2012) analysed their results by using the different data sets as they could not access the socio-economic information of the surgery inquirers group and used such information from the dating service group instead. It caused scepticism to the study since the measurement of the economics returns to the plastic surgery did not come from the same individuals. To contribute to the existing rating methods, we had the employers themselves rate each job candidate for attractiveness and trustworthiness at the end of the experiment. It means that the study will have 400 assessors to assess candidates' beauty and trustworthiness scores. By so doing, this approach not only increases the reliability to the beauty measurement but also assures that the beauty premiums/penalties and the hiring decisions precisely-simultaneously originate from the same individuals, while the literature failed to address this issue and presumed the rating scores from one group could explain the employment behaviour of the another. Moreover, we assure the consistency of the quality of the photos as they were taken by the same individual (the author): under approval from the Department of Corrections and support from the probation officers. Finally, our cosmetic surgery simulation refined the reservation in Lee and Ryu (2012), when it can compare the within-individual economics returns to cosmetic surgery.

\section{EXPERIMENTAL DESIGN}

This study employs the choice experiment (CEs) technique to investigate the labour market impact of criminal history records and physical attractiveness. CE is a statistical designed theory that allows the researcher to examine the respondent's evaluation of goods attributes by requiring the 
respondent to choose their most preferred one among a series of alternatives differed in terms of attribute levels. And the process for CE design are as follows:

\subsection{Subjects Preparation}

After the Research Ethics Review Committee for Research Involving Human, Research Participants, Health Science Group, Chulalongkorn University approved of the methodology, 27 newly released prisoners were randomly asked to volunteer as subjects of the experiments. To simulate the job-seeking situation of newly released prisoners as realistic as possible, the requirement for probation officers to recruit the volunteers are in this scenario:

- They had not been released for longer than six months,

- The recruitment is random and unbiased,

- There is a variety of types of criminal offences among the volunteers.

First, after signing their consent forms, their head-to-shoulder photos were collected at the Department of Probation on behalf of the Ministry of Justice. Since over $85 \%$ of volunteers were male, this study omitted female volunteers and male volunteers whose ages were under 20 and over 50. In so doing, we could avoid gender preference in the experiments and emphasis on the impact of cosmetic surgery on male ex-prisoners whose ages were in the range of Thai labour market demand. Then 18 male ex-prisoners' photos were used in the study. Next, the Photoshop and other graphics related software were used to simulate the after cosmetic surgery faces by graphic designers. Following ISAPS's statistics of most common procedures in Thailand in 2017 (ISAPS, 2018), the combination of rhinoplasty, eyelid surgery, facial contouring (fat-grafting face), facelift-brow lift, and lips shaping, were simulated to each male prisoner. The stimulations ended when the facial attractiveness rating scores (by 12 male and female assessors) reached above average: more than three from the five-point scale where one is least attractive, three is average looking, and five is very attractive. While field experiments in Pager (2003) and Pager et al. (2009) used matched pairs fictitious resumes that differed only in the criminal background, we conducted the CEs, in which two job candidates (ex-prisoners/subjects) represented two options in each choice set differing in the criminal background and facial attractiveness. Finally, to mostly extract the beauty premiums from experiments, they comprised occupations/positions in which physical appearance is agreed to be significant, such as sales, marketing, advertisement, and customer service-related officers. With this technique, the cosmetic surgery is expected to maximize the labour market return in the experiments.

\subsection{Development of Attributes (variables) and its Levels}

This study aims to test for the effect of facial attractiveness acquired from cosmetic surgery on labour market outcomes in the open records setting where the ex-prisoners expose his criminal history or/and the employers have access to this information. Thus, cosmetic surgery, headshoulder photos of male ex-prisoners, criminal history records, and salary were the three main attributes. Considering the job candidate simulated for cosmetic surgery or otherwise, the head-toshoulder photo of the candidate was attached in the choice set following the criteria. And the same approach was applied to criminal history records and salary attributes. The combination of all attributes and their levels allows us to investigate how employers evaluate each attribute (each 
qualification of candidates) and make their hiring decision. All of the attribute names and their respective levels are demonstrated in Table 1.

Table 1: Attributes and Descriptions

\begin{tabular}{llll}
\hline \hline Attributes & Levels & Description & $\begin{array}{l}\text { Variable names used in } \\
\text { models }\end{array}$ \\
\hline $\begin{array}{l}\text { Cosmetic } \\
\text { surgery }\end{array}$ & $\begin{array}{l}\text { Yes } \\
\text { No }\end{array}$ & $\begin{array}{l}\text { Whether the candidate } \\
\text { has undergone cosmetic } \\
\text { simulation or not? }\end{array}$ & $\begin{array}{l}\text { Surgery } \\
\text { No surgery }\end{array}$ \\
$\begin{array}{l}\text { Criminal history } \\
\text { records }\end{array}$ & $\begin{array}{l}\text { Yes } \\
\text { No }\end{array}$ & $\begin{array}{l}\text { Whether candidate has } \\
\text { served time in prison or } \\
\text { not? }\end{array}$ & $\begin{array}{l}\text { Crime } \\
\text { No Crime }\end{array}$ \\
$\begin{array}{l}\text { Head-shoulder } \\
\text { photo of male } \\
\text { ex-prisoner }\end{array}$ & 18 levels $(18$ prisoners $)$ & $\begin{array}{l}\text { Eighteen prisoners } \\
\text { perform as the job } \\
\text { candidates }\end{array}$ & $\begin{array}{l}\text { Mr. A-Mr. R } \\
\text { (Prisoner A-R) }\end{array}$ \\
$\begin{array}{l}\text { Salary } \\
\text { Salary }\end{array}$ & $\begin{array}{l}\text { The salary levels of } \\
\text { candidates were adapted from } \\
\text { The Informal Employment } \\
\text { Survey 2018 (NSO, 2018) }\end{array}$ \\
\hline \hline
\end{tabular}

\subsection{Generating Choice Sets}

The CE approach allows researchers to conduct field experiments in which they can vary experiment conditions while other factors that might affect the outcome are systematically controlled. In this study, each matched pair of candidates in each choice set had productivityrelated characteristics held equivalents, such as sex, age, education level, and experience. The main differences were such that cosmetic surgery, criminal history records, and salaries. To generate the design, we followed Aizaki (2012) and the function rotation.design in survival package, support.CEs in R statistical software version 1.2.1335 was used. If we apply full factorial designs, it will end up with $2 \times 2 \times 2 \times 18=144$ combinations. However, implementing full factorial designs could create a more psychological burden of answering too many questions to the respondent. Thus, we were motivated to reduce the size and implement the halffactorial design where only the main effects were drawn into analysed. First, we instructed the package to produce the halffactorial design, which randomly selected a particular fraction of the full factorials where the particular effect of interest can be estimated as efficiently as possible. And applying half-design shall not be problematic since Louviere, Hensher, and Swait (2000) suggested the main effects and two-way interaction account for 70-90\% and 5-15\% of explained variance, respectively. Consequently, with half-factorials design, the 72 choice sets, each of two alternatives, were randomly generated regarding orthogonality for that all combinations in the design were not correlated. Next, we instructed the CEs.package to divide 72 choice sets into six sub-blocks to limit the respondents' task. Thus, all 72 choice sets would create six versions of questionnaires with 12 choice sets each (plus four manipulation checks), in which 18 prisoner job candidates were randomly match-paired and randomly assigned for: cosmetic surgery, criminal history records, and salary, receptively.

Then, the shifting method was applied wherein the second alternative, all attributes were added for one constant level to create the shifting design. For example, refers to Table 1, if the first 
alternative shows levels combination of Yes: the candidate underwent Cosmetic surgery simulation, Yes: the candidate has a criminal history, A: Mr. A as prisoner job candidate, and salary of 15,000 baht. Applying the shifting method, the second alternative of this choice set composed of No, No, B, and 12,000 baht. Thus, in a particular choice set composed of 2 alternatives (2 candidates), only one alternative was attached with a photo of a job candidate who underwent cosmetic surgery simulation. The same approach was applied to criminal history records and salary attributes. In doing so, the impacts of the beauty premiums from cosmetic surgery and penalties from criminal records are more effectively extracted since. It also limits the confusion to the respondent of having the same level of the same attribute repeated in a choice set when the shifting method was not applied. After that, the six versions of the questionnaires were used in both the formal and informal sectors. The main differences are that the positions/occupations and salary levels were adjusted to be close to the statistics of employment in each sector, referring statistics from The Informal Employment Survey, 2018, (NSO, 2018). Finally, all of the 18 ex-prisoners performed as agents to help us investigate the labour market impacts of cosmetic surgery and criminal history records. The experiments in which the prisoners job candidate was assigned to have a criminal history record in some particular choice sets and assigned to not have them in the others. The same method was also applied to cosmetic surgery and salary attributes. Thus, each prisoner was investigated whether his job opportunity and income decreased or increased according to those qualities.

\section{Figure 1: Example of Choice Sets of Experiments in the Formal Sector}

In case you are recruiting a new officer for a salesperson with a requirement of age between 25 and 35 and you are having this scenario: 2 candidates: both 29, high school graduates, and having related experiences, computer skills, and English proficiency. Whom would you like to hire taking into consideration of their qualifications and numeration? (The respondent required to select one option)

Criminal history records

Salary

I choose

Additional comment on your

hiring and not hiring decision

(optional)

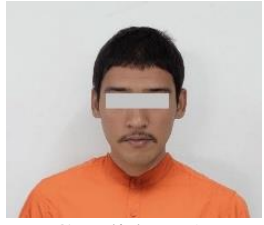

Candidate A.

No

12,000 THB (384 USD)

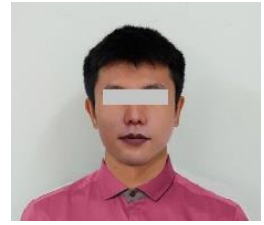

Candidate B.

Yes

15,000 THB (479 USD)

Remark: (1) Due to sensitive matter, the profile photos above are eye-closed with gray taps. However, the photos in all experiments are face fully shown. (2) For the experiment in the informal sector, the occupations/positions and salary level were adjusted to suit the statistics of informal labour sector.

Figure 1 shows how the choice set looks like in questionnaires for the experiments. Employers were presented with a variety of prisoner job candidates in a questionnaire and required to hire only one candidate in each matched pair for 12 choice sets. To illustrate this, if the employer hires candidate B, this implies that the employer evaluates candidate B as more productive, although he has a criminal history and is attached with a higher salary. Moreover, in the case that respondent 
rates candidate $\mathrm{B}$ as more attractive than candidate $\mathrm{A}$ and the trustworthiness scores of both candidates is lower than their beauty rating scores in a so-called: the manipulation check. These imply that the beauty premiums manifest, the hiring decision mainly comes from attractiveness rather than trustworthiness, and 'beauty' has more impact than the criminal history records factor. Moreover, the manipulation check is more contributive when we want to examine the beauty premiums from groups, such as prisoners whose looks can appeal as more alarming. (See the example of manipulation check in Figure 2).

\section{Figure 2: Example of Manipulation Checks for Both Sectors}

The assessment choice set 1: With respect to candidate's age, how many score would you rate the person's facial attractiveness and trustworthiness on the scale of 1 to 5 . ( 1 is unattractive/untrustworthy, 3 is moderate, and 5 is strikingly attractive/highly trustworthy)

Beauty score
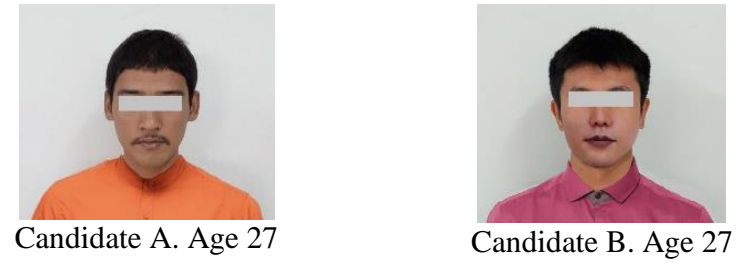

Trustworthiness score

\section{DATA COLLECTION}

\section{Respondents and Administration of Choice Experiments}

Since number of employers in both the formal and informal sectors are considered as an infinite population because all employers do not necessarily register to the system. This study used Roscoe (1975) sample calculation technique below:

$$
N=\left(\frac{Z_{c} \sigma}{e_{m}}\right)^{2}
$$

Thus, with the requirement of $\mathrm{Z}=1.96,(\alpha=0.5)$, and $e_{m}=1 / 10$, the sample size is 384.16 .

Therefore, the number of the respondent $(\mathrm{N})=408$, thus 408 experiments (questionnaires) were randomly conducted with 400 respondents in private businesses in Bangkok and the surrounding areas. Using purposive sampling: a respondent must be the person responsible for making the hiring decision. The data sets compose 204 sets of responses from private business owners/recruiters: approximately 204 organizations in the formal sector and 204 sets of responses from local business owners: 204 local businesses in the informal labour sector. The private sector was chosen for this study since, in many cases, they were often found to be unlikely to welcome prisoners into their organizations. Moreover, even though this study focused on the occupation in which the beauty is significant, we were able to collect 408 sets of responses of employers from 
various industries, such as food, transport, manufacturing, telecommunication, electronics, and hospitality. Finally, the respondent data sets from both the formal and informal labour sectors were separately constructed following Aizaki and Nishimura (2008) and analysed in R-programme using the clogit function (Aizaki, 2012) under Conditional Logit theory.

\section{ESTIMATION STRATEGY AND RESULTS}

\section{Modeling Strategy}

The choice experiments (CEs) developed by Louviere and Hensher (1982), Louviere and Woodworth (1983), and Louviere et al. (2000) which applies the same framework with the contingent valuation in McFadden (1973)'s Random utility model. Concerning original framework, the indirect utility function $(U)$ for each respondent $(i)$ composes of the deterministic element $(V)$ and stochastic elements $(e)$ where $(V)$ denotes the linear index of the attributes $(X)$ and (e) represents unobservable impacts on individual decision. And the utility is often specified to be linear in parameters and expressed as:

$$
U_{i j}=V_{i j}\left(X_{i j}\right)+e i j=b X_{i j}+e_{i j}
$$

The key assumption that each individual will maximize their utility and gains some utility from each attribute, the probability that a respondent (employer) prefers option $g$ (prisoner job candidate $g$ ) over option $h$ (prisoner job candidate $h$ ) indicates the probability that the utility related with option $g$ is greater than that in option $h$, as expressed in equation (2). That is, the individual ( $i$ ) will choose candidate $g$ over candidate $h$ if $U_{i g}>U_{i h}$, therefore, the chosen alternative is expressed as:

$$
\left.P\left[\left(U_{i g}>U_{i h}\right) \forall h \neq g\right]=P\left[V_{i g}-V_{i h}\right)>\left(e_{i h}-e_{i g}\right)\right]
$$

The basic assumption of applying RUM is that errors are independently and identically distributed following Type 1 extreme value (Gumbel) distribution. Thus, the Conditional (or multinomial) logit model (CLM) (McFadden, 1973) is applied as in equation (3) where $\mu$ is a scale parameter indicating the variance of unobserved portion of utility. And the scale parameter is typically set equal to 1 (Ben-Akiva \& Lerman, 2018).

$$
P\left(U_{i g}>U_{i h}, \forall h \neq g\right)=\frac{\exp \left(\mu V_{i g}\right)}{\sum_{j} \exp \left(\mu V_{i j}\right)}
$$

The WTP (or the implicit prices for attributes) shows how much money the employer is willing to sacrifice for a marginal change of prisoner job candidate attributes can be calculated as in equation (4) and the simplified equation (5) where $b_{c}$ is the coefficient on any of the attributes and the $b_{y}$ is the marginal utility of income and coefficient of the cost attributes (Hanley, Mourato, \& Wright, 2001).

$$
\begin{gathered}
W T P=b_{y}^{-1} \ln \left\{\frac{\sum_{i} \exp \left(V_{i}^{1}\right)}{\sum_{i} \exp \left(V_{i}^{0}\right)}\right\} \\
W T P=\frac{-b_{c}}{b_{y}}
\end{gathered}
$$


Adopting modeling strategy above with a systematic component of the utility supporting an implementation of choice experiment (Aizaki, 2012; Aizaki \& Nishimura, 2008), the basic utility specification $V_{i j}$ is expressed as:

$$
\begin{gathered}
V_{i j}=A S C_{i}+B_{\text {Surgery }} \text { Surgery }_{i j}+B_{\text {Prisoner }(i)} \text { Prisoner }_{(i)_{i j}}+B_{\text {Crime } \text { Crime }_{i j}}+ \\
B_{\text {Salary }} \text { Salary }_{i j}
\end{gathered}
$$

where $V_{i j}$ refers to an element of utility for the prisoner (i), ( $\mathrm{I}=$ alphabet A to R); ASC denotes an alternative specific constant; Surgery ${ }_{i j}$ is a dummy variable taking a value of 1 if the prisoner has undergone cosmetic surgery simulation, and 0 otherwise; Prisoner $(i)_{i j}$ is a dummy variable for each prisoner, for instance, $\operatorname{Prisoner}(A)_{i j}$ taking a value of 1 if it is prisoner $\mathrm{A}$, and 0 otherwise. $B_{\text {Crime }}$ Crime $_{i j}$ is a dummy variable indicating if the candidate has a criminal record. And

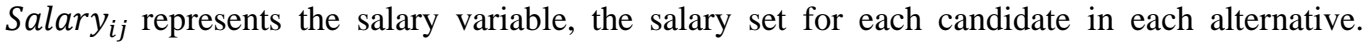
Conclusively, $B_{\text {Surgery, }}, B_{\text {Prisoner }(i)}, B_{\text {Crime }}$, and $B_{\text {Salary }}$ are coefficients corresponding with Surgery $_{i j}$, Prisoner $(i)_{i j}$, Crime $_{i j}$, and Salary $_{i j}$, respectively. The salary variable: the continuous variable is used to calculate the marginal willingness to pay of the respondents for the surgery and non-surgery groups. Finally, in the CLM model, one level of each dummy coded attribute was set as the based variable except for variable salary.

The based variables of the basic models were set as follows:

\section{Attribute}

Cosmetic Surgery

Criminal history records

Head-to-shoulder photo of prisoner

\author{
Based variable \\ No surgery \\ No crime \\ Mr. A. (Prisoner A.)
}

Finally, after executing function clogit in the survival package in $\mathrm{R}$ statistical software, the regression results of basic models regarding equation (6) for the formal and informal sectors are as follows where $\operatorname{exp(coef)~contributes~to~odd~ratios~or~the~increase~of~utility~of~each~attribute~}$ compared with based variables. Model 1 and 2 show the experiment results for in the formal and the informal sector, respectively. And the function mwtp calculated the MWTPs for attributes/levels and confidence interval (Krinsky \& Robb, 1986) as shown in Table 2 and 3, respectively.

\section{Model 1: Labour Opportunity for Prisoners in the Formal Sector}

\begin{tabular}{llllll}
\hline \hline & coef & exp(coef) & se(coef) & z & p \\
\hline ASC & 24.98 & $7.076 \mathrm{e}+10$ & $1.035 \mathrm{e}+03$ & 0.024 & 0.981 \\
Surgery & 0.562 & 1.754 & 0.059 & 9.486 & $<2 \mathrm{e}-16^{* * *}$ \\
Crime & -1.761 & 0.172 & 0.066 & -26.486 & $<2 \mathrm{e}-16^{* * *}$ \\
Salary & -2.478 & 0.084 & 0.206 & -12.036 & $<2 \mathrm{e}-16^{* * *}$ \\
\hline
\end{tabular}

Signif. codes: 0 '***' 0.001 '**' 0.01 '*' 0.05 '.' $0.1^{\text {' ' } 1} 1$

Likelihood ratio test $=3319$ on $21 \mathrm{df}, \mathrm{p}=<2.2 \mathrm{e}-16$

Number of choices $=7344$, number of events $=2448$, number of respondents $=204$

Rho-squared $=0.6169897$

Adjusted rho-squared $=0.6091813$ 
Akaike information criterion $(\mathrm{AIC})=2102.138$

Bayesian information criterion $(\mathrm{BIC})=2224.002$

Number of coefficients $=21$

Log likelihood at start $=-2689.403$

Log likelihood at convergence $=-1030.069$

Remark: Since we are interested in only main effects of cosmetic surgery and criminal history records, to make it concise and precise to readers, the regression results of variable head-shoulder photos of 18 prisoners (Mr. A to Mr. R) in the regression were removed in this written paper.

Table 2: Marginal Willingness to Pay in the Formal Sector

\begin{tabular}{llll}
\hline \hline & MWTP & $\mathbf{2 . 5 \%}$ & $\mathbf{9 7 . 5 \%}$ \\
\hline Surgery & 0.2267 & 0.1748 & 0.2895 \\
Crime & -0.7104 & -0.8331 & -0.6185 \\
\hline \hline
\end{tabular}

Method proposed by Krinsky \& Robb (1986)

Model 2: Labour Opportunity for Prisoners in the Informal Sector

\begin{tabular}{llllll}
\hline \hline & coef & $\exp ($ coef) & se(coef) & $\mathbf{z}$ & $\mathbf{p}$ \\
\hline ASC & 22.78 & $7.803 \mathrm{e}+09$ & 0.095 & 0.024 & 0.981 \\
Surgery & 0.559 & 1.750 & 0.046 & 12.013 & $<2 \mathrm{e}-16^{* * *}$ \\
Crime & -0.714 & 0.490 & 0.047 & -15.184 & $<2 \mathrm{e}-16^{* * *}$ \\
Salary & -1.855 & 0.156 & 0.155 & -11.927 & $<2 \mathrm{e}-16^{* * *}$ \\
\hline \hline
\end{tabular}

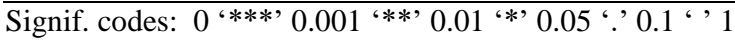

Likelihood ratio test $=2555$ on $21 \mathrm{df}, \mathrm{p}=<2.2 \mathrm{e}-16$

Number of choices $=7344$, number of events $=2448$, number of respondents $=204$

Rho-squared $=0.4750043$

Adjusted rho-squared $=0.4671959$

Akaike information criterion $($ AIC $)=2865.85$

Bayesian information criterion $(\mathrm{BIC})=2987.714$

Number of coefficients $=21$

Log likelihood at start $=-2689.403$

Log likelihood at convergence $=-1411.925$

Table 3: Marginal Willingness to Pay in the Informal Sector

\begin{tabular}{llll}
\hline \hline & MWTP & $\mathbf{2 . 5 \%}$ & $\mathbf{9 7 . 5 \%}$ \\
\hline Surgery & 0.3016 & 0.2420 & 0.3754 \\
Crime & -0.3848 & -0.4683 & -0.3186 \\
\hline
\end{tabular}

Method proposed by Krinsky \& Robb (1986)

Equation (6) produces Model 1 and 2 which represent results in the formal and the informal labour sector correspondingly. The variables 'surgery' are positively significant at $0.1 \%$ significance level in both sectors, wherein the formal sector, cosmetic surgery has a slightly more positive impact compared to the informal sector with the odds ratio or increase of utility of 1.754 . These indicate that from the experiments, most employers in both sectors preferred cosmetic surgery candidates (more attractive candidates) to non-surgery candidates. However, variables 'crime' in both sectors have negative coefficients with $0.1 \%$ significance level. These imply that relative to having no criminal history records, having criminal history records offered the labour penalty in the experiments: decreasing prisoners' job opportunities by $82.8 \%$ and $51 \%$ in the formal and the 
informal sector, respectively. The variables 'salary' are negatively significant at $1 \%$ significance level in both sectors, while the coefficient in the formal sector is larger. The MWTPs values for both sectors in Table 2 and Table 3 show that employers in the experiments were willing to pay an additional of 2,267 and 3,016 baht to the cosmetic surgery groups in the formal and the informal sector, respectively. While beauty generates greater premiums to prisoners in the experiments, the criminal history records reduced their potential earnings for 7,104 and 3,848 in the formal and the informal sector, respectively. When we used 'surgery', 'crime', and 'Mr. A' as the based variables, the results show that the 'no surgery' variables are negatively significant at $0.1 \%$ in both sectors. Relative to cosmetic surgery groups, the non-surgery groups have a decrease in job opportunities by $43 \%$ in the formal sector and $42.8 \%$ in the informal sector. When comparing these results from the basic model 1 and 2, it is explicitly observed that cosmetic surgery can perform as an aid for labour market re-entry to prisoners. The 'no crime' variables are positively significant at $0.1 \%$ with the odds ratio or the increase of utility of 5.817 and 2.042 in the formal and informal sector, respectively. These imply that most respondents in the experiments preferred job candidates with no criminal history records relative to the candidates with criminal history records.

Following Aizaki (2012) and Aizaki and Nishimura (2008), the additional models were conducted to investigate the impact of the respondent's characteristics on their evaluation of each attribute by

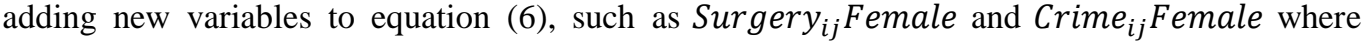
Female is a dummy variable taking a value of 1 if the respondent is female, and 0 otherwise. The interaction between two variables in the formula is calculated by using the operation Surgery:Female and Crime:Female, accordingly. Thus, the respondent characteristics such as gender, age, and experience interacted with the variables 'surgery' and 'crime' to investigate its impact on the respondent evaluation of candidates with cosmetic surgery and candidates with criminal history records. By gender, there is no significant effect of gender on the evaluation of the 'surgery' variable for both sectors, indicating that the respondent gender in the data sets had no significant impact on their valuation of the cosmetic surgery. Moreover, respondent gender also had no significant impact on the evaluation of the variable 'crime' for both sectors, implying that the stereotypes towards criminal history records presumably belong to the individuals' interpretation rather than gender difference. When respondent age interacted with 'crime' and 'surgery' variables, there is a negative impact of respondent age on the evaluation of 'surgery' variable with the odds ratio of 0.973 at $1 \%$ significance level in the formal sector, while it had no significant impact in the informal sector. And while the respondent age had no significant effect of the evaluation on the 'crime' variable in the formal sector, it had a positive impact in the informal sector with the odds ratio of 1.021 at $0.1 \%$ significance level. This implies that the older of the respondent age in the informal sector data set, the more preferable the respondents evaluate candidates with criminal history records. When the respondent experiences interacted, there is no significant impact on the evaluation of variable 'surgery' and 'crime' in the formal sector, wherein the informal sector, the respondent's experience had a negative impact on the variable 'crime' at $0.1 \%$ significance level: decreasing job opportunity by $3.2 \%$.

In conclusion, the results not only support the finding in literature but also add to the literature in two ways. Firstly, we showed that the criminal history records and low physical attractiveness are also one of the main barriers to prisoners' labour market re-entry in Thailand. Secondly, we can estimate the change of labour outcome of the same individuals when their situation of criminal records and physical attractiveness has changed. Although some limitation exists in this study where we used computer software to simulate cosmetic surgery, the approach supported us to 
investigate the cosmetic surgery's impact in the perspective that is difficult to find in the literature. Moreover, the simulation seems to be as effective as the real surgery when the results of the beauty premiums in experiments were congruent with the former study in that they showed the decreases in the recidivism rates in the cosmetic surgery group due to successive reintegration (Freedman et al., 1988; Spira et al., 1966).

\section{DISCUSSION AND POLICY IMPLICATIONS}

The current paper analyses the impact of the criminal record and physical attractiveness on job opportunities and incomes in both the formal and the informal sectors of Thai ex-prisoners. We conducted the experiments on the job positions and found that physical appearance is strongly significant for some types of jobs, such as a salesperson, marketing officer, and customer service officer. Results found no significant discrimination among industries. Thus, prisoner discrimination might not focus on a particular industry, but occupations and positions. While these barriers might have a significant negative impact on labour market return to ex-prisoners on the above occupations, they might have less penalty in occupations and positions where employees and customers have no interpersonal interaction. The results also show that both the stereotype towards individuals with criminal history records and the beauty premiums to attractive individuals contribute to the opportunities for further research and the reconsideration of current policies for alleviating discrimination and improving prisoners' success rate of re-entry. For example, since the experiments show the stereotype towards ex-prisoners where the information about them was mostly absorbed from the media, it is interesting to further research whether additional information, such as the certificates of good behaviour, basic work readiness skills, and training can be sent to potential employers. As the additional positive signals to reshape employer perceptions and sequentially improve the prisoners' success of labour market re-entry. For policy implication, even though this study shows the significant positive impacts of cosmetic surgery to ex-prisoners labour market returns, this study, however, does not suggest the necessity of cosmetic surgery but rather shows the significance of physical attractiveness influencing prisoners' employments. It could serve as a new piece of knowledge to policymakers who want to 'rebrand' the prisoners, such as the grooming or makeup training programme. Also, the government needs to acknowledge their people provide the opportunity for ex-prisoners.

\section{ACKNOWLEDGEMENT}

The authors gratefully appreciate the support of the Department of Probation on behalf of the Ministry of Justice, who kindly approved of collecting photos of 27 newly released prisoners. Also, the information from in dept-interviews with probation officers and newly released prisoners is greatly beneficial and informative to the study. We also appreciate the participation of all newly released prisoners who volunteered to have their photos used for the study. And the Research Centre for Social and Business Development. Co. Ltd. (SAB) for professionally distributing the questionnaires. 


\section{REFERENCES}

Agan, A., \& Starr, S. (2017). The effect of criminal records on access to employment. American Economic Review, 107(5), 560-564.

Ahmed, A. M., \& Lång, E. (2017). The employability of ex-offenders: a field experiment in the Swedish labor market. IZA journal of Labor Policy, 6(6), 1-23.

Aizaki, H. (2012). Basic Functions for Supporting an Implementation of Choice Experiments in R. Journal of Statistical Software, 50(CS2), 1-24.

Aizaki, H., \& Nishimura, K. (2008). Design and analysis of choice experiments using R: a brief introduction. Agricultural Information Research, 17(2), 86-94.

Babin, J. J., Hussey, A., Nikolsko-Rzhevskyy, A., \& Taylor, D. A. (2020). Beauty Premiums Among Academics. Economics of Education Review, 78, 102019. doi: 10.1016/j.econedurev.2020.102019

Ben-Akiva, M., \& Lerman, S. R. (2018). Discrete choice analysis: theory and application to travel demand. Cambridge: The MIT Press.

Bendick, M., Jackson, C. W., \& Reinoso, V. A. (1994). Measuring employment discrimination through controlled experiments. The review of black political economy, 23(1), 25-48.

Berggren, N., Jordahl, H., \& Poutvaara, P. (2010). The looks of a winner: Beauty and electoral success. Journal of Public Economics, 94(1), 8-15. doi: 10.1016/j.jpubeco.2009.11.002

Berscheid, E., \& Walster, E. (1974). Physical attractiveness. Advances in Experimental Social Psychology, 7, 157-215.

Biddle, J. E., \& Hamermesh, D. S. (1998). Beauty, productivity, and discrimination: Lawyers' looks and lucre. Journal of labor Economics, 16(1), 172-201.

Bóo, F., L., Rossi, M. A., \& Urzúa, S. S. (2013). The labor market return to an attractive face: Evidence from a field experiment. Economics Letters, 118(1), 170-172. doi: 10.1016/j.econlet.2012.10.016

Bushway, S. D. (2004). Labor market effects of permitting employer access to criminal history records. Journal of Contemporary Criminal Justice, 20(3), 276-291.

Cawley, J. (2004). The impact of obesity on wages. Journal of Human resources, 39(2), 451-474.

Chui, W. H., \& Cheng, K. K.Y. (2013). The mark of an ex-prisoner: Perceived discrimination and self-stigma of young men after prison in Hong Kong. Deviant Behavior, 34(8), 671-684.

Decker, S. H., Ortiz, N., Spohn, C., \& Hedberg, E. (2015). Criminal stigma, race, and ethnicity: The consequences of imprisonment for employment. Journal of Criminal Justice, 43(2), 108-121. doi: 10.1016/j.jcrimjus.2015.02.002

Department of Corrections. (2020a). Number of Convicted Prisoners by Type of offences. Retrieved from http://www.correct.go.th/eng/number_by_type_of_offences.html

Department of Corrections. (2020b). Recidivism Statistics Database. Retrieved from http://www.correct.go.th/recstats/index.php/th/sumReportCondition\#

Department of Corrections. (2020c). Thailand's prisoner population, 2019. Retrieved from http://www.correct.go.th/rt103pdf/report_result.php?date=2019-07-01\&report=

Dipboye, R. L., Arvey, R. D., \& Terpstra, D. E. (1977). Sex and physical attractiveness of raters and applicants as determinants of resume evaluations. Journal of Applied Psychology, 62(3), 288-294.

Dipboye, R. L., Fromkin, H. L., \& Wiback, K. (1975). Relative importance of applicant sex, attractiveness, and scholastic standing in evaluation of job applicant resumes. Journal of Applied Psychology, 60(1), 39-43. 
Eschholz, S. (2002). Racial composition of television offenders and viewers' fear of crime. Critical Criminology, 11(1), 41-60.

Fletcher, J. M. (2009). Beauty vs. brains: Early labor market outcomes of high school graduates. Economics Letters, 105(3), 321-325. doi: 10.1016/j.econlet.2009.09.006

Freedman, A. M., Warren, M. M., Cunningham, L. W., \& Blackwell, S. J. (1988). Cosmetic surgery and criminal rehabilitation. Southern medical journal, 81(9), 1113-1116.

Hamermesh, D. S., Meng, X., \& Zhang, J. (2002). Dress for success - does primping pay? Labour Economics, 9(3), 361-373. doi: 10.1016/S0927-5371(02)00014-3

Hanley, N., Mourato, S., \& Wright, R. E. (2001). Choice modelling approaches: a superior alternative for environmental valuatioin? Journal of economic surveys, 15(3), 435-462.

Harper, B. (2000). Beauty, stature and the labour market: A British cohort study. Oxford Bulletin of Economics and Statistics, 62, 771-800.

Holzer, H. J., Raphael, S., \& Stoll, M. A. (2006). Perceived criminality, criminal background checks, and the racial hiring practices of employers. The Journal of Law and Economics, 49(2), 451-480.

International Society of Aesthetic Plastic Surgery (ISAPS). (2018). ISAPS International survey on aesthetic/cosmetic procedure performed in 2017. Retrieved from https://www.isaps.org: https://www.isaps.org/wp-content/uploads/2018/10/ISAPS_2017_International_Study_ Cosmetic_Procedures.pdf

Kim, Y. C., \& Loury, G. C. (2018). Rebranding ex-convicts. Journal of Public Economic Theory, 20(3), 356-366. doi: 10.1111/jpet.12283

Krinsky, I., \& Robb, A. L. (1986). On approximating the statistical properties of elasticities. The Review of Economics and Statistics, 715-719.

Kurtzberg, R., Safar, H., \& Mandell, W. (1969). Plastic surgery in corrections. Fed. Probation, 33, 44-47.

Lee, S., \& Ryu, K. (2012). Plastic Surgery: Investment in human capital or consumption? Journal of Human Capital, 6(3), 224-250.

Louviere, J. J., \& Hensher, D. A. (1982). On the design and analysis of simulated choice or allocation experiments in travel choice modelling. Transportation research record, 890(1982), 11-17.

Louviere, J. J., Hensher, D. A., \& Swait, J. D. (2000). Stated choice methods: analysis and applications. Cambridge: Cambridge University Press.

Louviere, J. J., \& Woodworth, G. (1983). Design and analysis of simulated consumer choice or allocation experiments: an approach based on aggregate data. Journal of Marketing Research, 20(4), 350-367.

McFadden, D. (1973). Conditional logit analysis of qualitative choice behavior.

National Statistical Office Thailand (NSO). (2018). The Informal Employment 2018. Retrieved from http://web.nso.go.th/

Oreffice, S., \& Quintana-Domeque, C. (2016). Beauty, body size and wages: Evidence from a unique data set. Economics \& Human Biology, 22, 24-34. doi: 10.1016/j.ehb.2016.01.003

Pager, D. (2003). The mark of a criminal record. American journal of sociology, 108(5), 937-975.

Pager, D., Western, B., \& Sugie, N. (2009). Sequencing disadvantage: Barriers to employment facing young black and white men with criminal records. The ANNALS of the American Academy of Political and Social Science, 623(1), 195-213. Retrieved from https://www.ncbi.nlm.nih.gov/pmc/articles/PMC3583356/pdf/nihms-439026.pdf

Roscoe, J. T. (1975). Fundamental research statistics for the behavioral sciences ( $2^{\text {nd }}$ Ed.). New York: Holt, Rinehart, and Winston. 
Siwach, G. (2018). Unemployment shocks for individuals on the margin: Exploring recidivism effects. Labour Economics, 52, 231-244. doi: 10.1016/j.labeco.2018.02.001

Sohn, K. (2015). The height premium in Indonesia. Economics \& Human Biology, 16, 1-15. doi: 10.1016/j.ehb.2013.12.011

Solinas-Saunders, M., Stacer, M. J., \& Guy, R. (2015). Ex-offender barriers to employment: racial disparities in labor markets with asymmetric information. Journal of Crime \& Justice, 38(2), 249-269. doi: 10.1080/0735648x.2013.870492

Spira, M., Chizen, J. H., Gerow, F. J., \& Hardy, S. B. (1966). Plastic surgery in the Texas prison system. British Journal of Plastic Surgery, 19, 364-371. doi: 10.1016/S00071226(66)80080-2

Tao, H. L. (2014). Height, weight, and entry earnings of female graduates in Taiwan. Economics \& Human Biology, 13, 85-98. doi: 10.1016/j.ehb.2013.12.006

Visher, C. A., Debus-Sherrill, S. A., \& Yahner, J. (2011). Employment After Prison: A Longitudinal Study of Former Prisoners. Justice Quarterly, 28(5), 698-718. doi: 10.1080/07418825.2010.535553

Young, N. C. J., \& Powell, G. N. (2015). Hiring ex-offenders: A theoretical model. Human Resource Management Review, 25(3), 298-312. 